\title{
CONSIDERAÇõES SOBRE O USO E A SEMÂNTICA DE ALGUMAS PALAVRAS EMPREGADAS NOS TEXTOS DA ReBEn NO PERIODO DE 1974-1978.
}

\author{
Ir. Cleamaria Simões, ascj.*
}

\begin{tabular}{l|l}
\cline { 2 - 2 } & $\operatorname{ReBEn} / 03$ \\
\hline
\end{tabular}

SIMÕES, C., Considerações sobre o uso e a semântica de algumas palavras empregadas nos textos da ReE.En no período de 1974-1978. Rev. Bras. Enf.; DF, 33 : 305-309, 1980.

Este trabalho é derivado de uma Tese de Mestrado que se propôs a estudar a Terminologia Básica de Enfermagem no Brasil, quando procurou também elaborar um Glossário de Enfermagem. O seu objetivo é, portanto, mostrar um dos aspectos das conclusões a que se chegou, em relação ao uso e ao significado de algumas palavras encontradas nos textos de artigos da ReBEn.

$\mathrm{Na}$ organização do trabalho original, procurou-se conservar o quanto possível a integridade das palavras utilizadas pelos autores dos artigos. Pode-se observar a inexistência de uma linguagem homogênea na comunicação entre os integrantes do grupo profissional de enfermeiros. Nem sempre houve emprego exa.to das palavras na indicação do conceito desejado, pois a escolha da mesma se dá às vezes por aproximação, isto é, escolhe-se aquelas que se adaptam melhor à intenção em um processo de intercâmbio sócio-profissional da comunicação.

Observou-se que, nos textos da ReBEn, o uso de certas palavras e/ou expressões não é uniforme no decorrer da apresentação do assunto: multiplicam-se as palavras querendo significar a mesma coisa, por vezes, com conotações diferentes, dificultando a interpretação do pensamento do autor. Para elucidar essa colocação, são mencionados alguns exemplos: Atividade de Enfermagem, Atendimento de Enfermagem e Assistência de Enfermagem. Estes sintagmas foram mencionados ora de uma forma, ora de outra nos artigos lidos da ReBEn.

Essa imprecisão no uso e no significado de alguns sintagmas restringe a possibilidade de maior enriquecimento vocabular. Esta situação pode ser tam-

* Mestra em Ciências de Enfermagem. Professora na Faculdade de Enfermagem Sagrado Coração de Jesus - Bauru-SP. 
SIMÕES, C., Considerações sobre o uso e a semântica de algumas palavras empregadas nos textos da ReEEn no período de 1974-1978. Rev. Bras. Enf.; DF, 33 : 305-309, 1980.

bém interpretada pela dificuldade de criar, para cada referência psicológica, um signo adequado, com significado preciso. Conseqüentemente, dessa flutuação do significado básico de cada signo, pode decorrer deficiência na comunicação entre os elementos do grupo profissional.

Pode-se também observar que:

01 - Algumas palavras vêm sendo consagradas pelo uso com sentido impróprio. Por exemplo:

. os conceitos "assistência espiritual" e "religiosa" têm sido utilizados e mencionados como sinônimos. No entanto, são distintos, embora haja significativa afinidade entre um e outro.

- "processo de enfermagem" é um conceito freqüentemente mal empregado. Trata-se de uma entidade abstrata, portanto, independe das intenções das pessoas. Em sua essência, o processo assistencial existe desde que a pessoa entre num sistema de trabalho organizado ou não. Percebeu-se que, atualmente, há enfermeiros que falam em usar o "processo de enfermagem" ou implementar o "processo de enfermagem" como se fosse algo existente e que possa ser submetido a um experimento. A implicação está em o enfermeiro sistematizar o processo assistencial através de uma metodologia adequada, ou seja, colocar o trabalho até então desenvolvido assistematicamente numa determinada ordem lógica e metodológica. Poder-se-ia então referir-se mais especificamente a uma assistência metodológica à pessoa (pessoa aqui entendida também grupos da comunidade e a própria comunidade) numa situação/problema. Se a metodologia do processo de enfermagem vem ou não beneficiar o assistido é outra questão que mereceria reflexão. houve também impropriedade no uso do sintagma "Histórico de Enfermagem", como vem sendo usado. A análise etimológica indica que "Histórico é a narração cronologicamente documentada, de acontecimentos passados" (1). Na verdade, com o Histórico de Enfermagem, parece-nos não haver a preocupação primordial de se fazer uma disposição cronológica de fatos, mas, muito mais, de se descrever a situação/problema que se apresenta. Em vista disso, houve sugestões de algumas enfermeiras para substituir a palavra "Histórico de Enfermagem" por "Descrição da Situação do Cliente". Este novo enfoque pode ter seus fundamentos na teoria gestaltista, pois, no momento em que se descreve a situação do cliente, o enfermeiro é orientado por aspectos fenomenológicos, ou seja, descreve a situação imediata como ele a percebe. Entretanto, o diagnóstico de enfermagem não será feito sobre esses dados coletados, mas na relação que se estabelece entre os mesmos, ou seja, na interpretação da situação do cliente. Isto porque as diversas informações coletadas separadamente não constituem toda realidade da situação/ problema. Portanto, a percepção da situação/problema depende da interação que se estabelece entre o enfermeiro e a pessoa assistida e do inter-relacionamento que o enfermeiro faz dos fatos coletados.

com relação à "Interação Enfermeiro/Paciente" e "Relacionamento Enfermeiro/Paciente", essas expressões têm sido usadas com o mesmo significado. Entretanto, sociologicamente há significação mais específica para as duas expressões. Enquanto Interação compreende o contato pessoal entre duas pessoas, não sendo obrigatório o envolvimento interpessoal das mesmas, "Re- 
SIMÓES, C., Considerações sobre o uso e a semântica de algumas palavras empregadas nus textos da ReEiEn no período de 1974-1978. Rev. Bras. Enf.; DF, 33 : 305-309, 1980.

lacionamento" tem sua semântica diversa e implica em envolvimento interpessoal, podendo gerar influência recíproca decorrente do clima de afinidade que se desenvolve entre elas.

02 - Alguns termos, por serem utilizados com significado variável, comportam uma análise mais pormenorizada. Por exemplo: pela análise dos textos chegou-se a identificar algumas categorias específicas da "Ação de Enfermagem", como:

a) ação sinérgica, quanto à ação prestada pela equipe de saúde;

b) ação estimuladora do rendimento da instituição pela maximização do rendimento e a minimização dos custos;

c) ação inibidora de riscos e sofrimentos desnecessários por ação iatrogênica ou por omissão;

d) ação complementar, suplementar ou substitutiva ao autocuidado.

Com relação ao sintagma "Serviço de Enfermagem", nas consultas complementares, foi sugerida a substituição por "Trabalho de Enfermagem", devido a possibilidade de dupla interpretação dos termos: Serviço X Serviço e Atividade $\mathrm{X}$ Tarefa $\mathrm{X}$ Operação.

03 - Várias palavras, embora estivessem inseridas nos critérios de inclusão, por ocasião da coleta de palavras dos artigos da ReBEn, não foram consideradas pelas seguintes razões:

a) palavras empregadas indevidamente para formar o sintagma, exemplo: contato enfermeiro/paciente;

b) palavras obsoletas, por exemplo: enfermeira diplomada;

c) palavras não significativas fora do contexto (sinsemânticas), não trazendo relevância para o glossário. Exemplo: Assuntos de Enfermagem, trabalho em enfermagem, semestres de enfermagem, imagem técnica da enfermagem, percepção da enfermagem, pessoas de enfermagem, exercentes de enfermagem, posição de enfermagem, alçada da enfermagem, imagem de enfermeira e atenção de enfermagem. Este último sintagma foi largamente usado pelos enfermeiros na mais variada simbologia. Exemplo: atenção primária em consultas de enfermagem, ações de atenção pediátrica, atenção de saúde, atenção de enfermagem, atenção integral ao indivíduo, atenção à família e à comunidade, sistema de atenção à saúde, atenção de enfermagem inadequada, atenção direta, prestar atenção de enfermagem, processo de atenção de enfermagem e outros semelhantes.

No contexto em que foi usada atenção, a sua acepção é a mesma que cuidado ou assistência e resulta de uma introdução do espanhol, já que em português a palavra atenção significa "aplicação cuidadosa da mente a alguma coisa; concentração, reflexão, aplicação" (1) não existindo em nossa língua a acepção do espanhol de "acción $y$ efecto do atender" (2).

04 - Alguns textos evidenciam a tendência de substituir palavras ou de atribuir-lhes novas significações:

as palavras Cliente e Paciente têm, nos textos, os mais variados usos. De acordo com os dicionários etimológicos, Cliente é também denominado doente e se caracteriza como aquela pessoa que "procura" a proteção de alguém. Entretanto, etimologicamente, doente não é denominado cliente. $P a$ ciente refere-se à pessoa que tem tolerância à dor, ao sofredor ou também ao objeto em que se emprega a ação do agente.

(1) HOLANDA, sd.

(2) NUEVO DIC. ILUSTRADO DE LA LENGUA ESPAÑOLA, 1970. 
SIMÕES, C., Considerações sobre o uso e a semântica de algumas palavras empregadas nos textos da Ref.En no período de 1974-1973. Rev. Bras. Enf.; DF, 33 : 305-309, 1989.

A semântica das palavras evolui por influência de inúmeros fatores, principalmente o histórico e o social, como pode ainda ser modificada pelos grupos sociais de determinada profissão. Acreditamos que em consonância com as novas abordagens filosóficas de enfermagem, devemos preferir um termo que tenha significado condizente com a realidade atual da prática da enfermagem. A pessoa que necessita de assistência de enfermagem não deve ser meramente recebedor dos cuidados planejados e executados pela equipe de enfermagem, mas deve participar do planejamento da própria assistência juntamente com o enfermeiro. Portanto deixa de ser simplesmente o objeto em que se emprega a ação do agente. Ele mesmo é o sujeito da assistência e o enfermeiro, o facilitador dessa ação. O termo paciente poderia se restringir àquelas pessoas impossibilitadas de participarem da planejamento de sua própria assistência. Então seriam pacientes apenas aquelas pessoas com dependência total de enfermagem, cuja sobrevivência dependeria, em grande escala, da ação e dos cuidados de enfermagem. Exemplo: paciente inconsciente.

Assim sendo, a palavra cliente poderia ser incluída na terminologia profissional como aquela pessoa sadia ou doente, hospitalizada ou não, que necessita de alguma forma da assistência de enfermagem.

com relação a "atividades delegadas", a que se referem alguns autores, (não se trata simplesmente de atividades, mas de funçöes delegadas), ROGERS (1972) relata claramente que a profissão de enfermagem existe para servir aos seus próprios fins e nenhuma profissão delega poderes a outra. Cada profissão deve determinar suas próprias fronteiras dentro do contexto da necessidade social. A Enfermagem, como profissão autônoma, não tem nenhuma função dependente, mas, como todas as outras profissões, tem muitas "funções colaboradoras" que são indispensáveis para dotar a sociedade do mais qualificado serviço que qualquer profissão pode oferecer.

Esse termo "funçōes médicas delegadas" remonta desde o ano de 1958, yuando, em Genebra, a Comissão de Peritos em Enfermagem da OMS, aludindo-se sobre as funções da enfermeira de saúde pública, delega-lhes algumas funções da competência médica. Porém, essa determinação coube aos países decidirem. No Brasil, a Fundação do Serviço Especial de Saúde Pública foi a primeira a aplicar esse conceito.

As palavras Enfermagem e Enfermeiro, atualmente, passam por um processo metassêmico. A semântica não se restringe mais apenas àquela significação conferida pela sua etimologia. Hodiernamente, o Enfermeiro não dá assistência apenas ao enfermo. Diz ROGERS (1972) a "Enfermagem se preocupa com as pessoas, todas as pessoas, saudáveis e doentes, ricos e pobres, jovens $e$ velhos, onde quer que esteja no trabalho e na recreação. Preocupa-se com os seres humanos, somente alguns dos quais estão doentes". (1).

O propósito atual da enfermagem é atingir o homem todo como pessoa, encaminhando-o para o autocuidado ou auto-ajuda, principalmente tornando-lhe acessíveis às agências de saúde, para usufruir dos benefícios oferecidos pela sociedade.

O enfermeiro ajuda as pessoas a viverem no melhor nível possível de saúde dentro das próprias condições. No espírito do Plano Decenal de Saúde, o enfermeiro procura contrbuir para que seja proporcionada maior cobertu-

(1) ROGERS, 1972. n. 43. 
SIMÕES, C., Considerações sobre o uso e a semântica de algumas palavras empregadas nos textos da ReP.En no período de 1974-1978. Rev. Bras. Enf.; DF, 33 : 305-309, 1980.

ra assistencial, alargando seu campo de atuação e descobrindo novas formas de praticar a enfermagem.

Assim, a causa da nobilitação semântica das palavras Enfermagem e Enfermeiro são as circunstâncias históricas atuais, pois, como sempre, é o fator histórico o maior responsável pelas mudanças constantes do significado das profissões e em decorrência de seus próprios conceitos.

Percebe-se pelo exposto que, entre os enfermeiros, há excesso de termos com significado semelhante como também a impropriedade no uso de algumas palavras, por vezes, alterando a sua semântica. É também exemplo o uso inadequado de algumas preposições, exemplo: "do", "de", "em", modificando o significado de sintagmas. Exemplo: Trabalho de Equipe, Trabalho em Equipe, Planejamento de Enfermagem e Planejamento em Enfermagem, Vigilância de Enfermagem e Vigilância em Enfermagem, embora o texto quisesse expressar a mesma acepção em cada colocação sintagmática.

Além dessas, outras impropriedades aconteceram com a colocação de palavras para formar um sintagma, exemplos: Integral Atendimento ao Paciente, Tratamento de Enfermagem Preventivo, Assistência Integral de Enfermagem Planejada e outras. Talvez seja resultado de expressões estrangeiras traduzidas incorretamente?

O uso e o significado da palavra "Profissional" foi bastante divergente Para vários enfermeiros todas as categorias de pessoal de enfermagem foram consideradas "Profissionais de Enfermagem". Entretanto, a Lei n. ${ }^{\circ} 6.229 / 75$, que organiza a estrutura Nacional de Saúde, nos facilita um posicionamento a respeito. Nos itens I, alínea " $j$ ", e III, alíneas "a" e "b", mencionam que o profissional é o enfermeiro e as demais categorias: Técnico de Enfermagem, Auxiliar de Enfermagem e o Atendente de Enfermagem exercem uma ocupação de Enfermagem em níveis diferentes.

A Enfermagem necessita de uma Terminologia própria para que possa desenvolver-se como ciência. $\mathrm{E}$ esta dificuldade explica-se por estar a Enfermagem em um estágio incipiente na estruturação de suas bases científicas. Necessário se faz que os enfermeiros empreguem na esfera da prática da Enfermagem as palavras exatas. DOURADO (1978) referiu (...) "o universo de comunicação na enfermagem: necessitamos utilizar os mesmos termos para nos compreendermos" (1).

O uso do glossário de enfermagem poclerá contribuir para o surgimento de outras palavras que traduzam mais especificamente a prática profissional. Isto ocorrerá na medida em que ele vier favorecer o espírito crítico e criativo dos enfermeiros para a análise e proposições de uma Terminologia específica. Este fato estabeleceria um "feed-back" entre a prática e a suposta teoria de enfermagem representada no enfoque conceitual pelo glossário. Partindo da premissa de que a estimulação recíproca entre teoria de enfermagem e a prática de enfermagem provoca desenvolvimento científico, estamos diante de uma citação que, se explorada, poderá suscitar um crescimento vocabular. Menciona BACHRACH (1974), "d̀ medida que cresce o corpo de literatura em uma área particular, o interesse dos pesquisadores é estimulado e diferentes aspecios da área são submetidos a estudos mais intensivos". (2).

(1) DOURADO, H. G. Rev. Bras. Enf. 31(3): 298, 1978.

(2) BACHRACH, 1974, p. 89. 